\title{
Actividades enzimáticas en aislamientos bacterianos de tractos digestivos de larvas y del contenido de pupas de Automeris zugana y Rothschildia lebeau (Lepidoptera: Saturniidae)
}

\author{
Adrián Pinto-Tomás ${ }^{1}$, Lorena Uribe-Lorío ${ }^{1}$, John Blanco ${ }^{1}$, Gustavo Fontecha ${ }^{1}$, César Rodríguez ${ }^{1}$, \\ Marielos Mora ${ }^{1}$, Daniel Janzen², Felipe Chavarría ${ }^{3}$, Joel Díaz ${ }^{3} \&$ Ana Sittenfeld ${ }^{1}$ \\ 1 Centro de Investigación en Biología Celular y Molecular (CIBCM), Universidad de Costa Rica, 2060, San José, Costa \\ Rica. Tel: +506 207 3204, Fax +506 207 3190; asitten@racsa.co.cr \\ 2 Department of Biology, University of Pennsylvannia, Philadelphia, PA 19104; djanzen@sas.upenn.edu \\ 3 Área de Conservación Guanacaste (ACG), 169-5000 Liberia, Guanacaste, Costa Rica
}

Recibido 10-XII-2002. Corregido 17-VIII-2006. Aceptado 12-I-2007.

\begin{abstract}
Enzymatic activities of bacteria isolated from the digestive tract of caterpillars and the pupal content of Automeris zugana and Rothschildia lebeau (Lepidoptera: Saturniidae). The enzymatic activities of bacteria isolated from the digestive tracts of caterpillars and the pupal contents of Automeris zugana and Rothschildia lebeau was studied. This digestive tract represents an extreme microenvironment due to its high $\mathrm{pH}$ and presence of antimicrobial substances secreted by the insect or derived from ingested plant tissue. At the same time, it contains large amounts of nutrient-rich food, for which microbes may compete among themselves and with the caterpillar. There is little information about the microbiota associated with tropical caterpillar guts, although bacteria from different genera have been isolated from gut and pupae samples. The study of the enzymatic activities generated by these organisms constitutes a starting point to understand their metabolic and physiological relationships with their hosts, and to find enzymes that have potential biotechnological applications. In this study we evaluated several enzymatic activities in two collections of bacteria isolated from caterpillar guts and pupae of the tropical lepidopteran species A. zugana and R. lebeau. Bacteria grown under aerobic conditions were tested for an array of enzymes, including gelatinases, caseinases, lipases, esterases, cellulases, xylanases, amylases and chitinases. Both collections displayed similar patterns of enzymatic activity. No isolate showed activity for all enzymatic tests, but as a whole, at least some bacteria in each collection were able to degrade each substrate tested. Isolates with the same taxonomic identification obtained from caterpillar guts and pupae had almost the same enzymatic activities. In both collections, it was possible to group bacterial isolates according to their enzyme activity pattern. In addition to a heterogeneous ensemble of isolates exhibiting two or less enzymatic activities, there were two groups with at least five activities that showed an apparent specialization for the substrates they were able to use. The first consisted exclusively of isolates of the family Enterobacteriaceae, which were positive for lipolytic and chitinolytic activities, but completely lacked amylasic, cellulolytic and xylanolytic activities. The second group, composed mainly of Gram-positive rods, exhibited the opposite pattern: they were positive for amylasic, cellulolytic and xylanolytic activities, lacked chitinolytic activity and had few isolates with lipolytic activity. This work forms the foundation for future research to explore the biotechnological potential of bacterial isolates from caterpillar guts. Rev. Biol. Trop. 55 (2): 401-415. Epub 2007 June, 29.
\end{abstract}

Key words: Saturniidae, caterpillar, bacterial enzymes, Automeris zugana, Rothschildia lebeau, Área de Conservación Guanacaste, Costa Rica.

En ecosistemas silvestres los insectos consumen el $10 \%$ de la producción vegetal del bosque (Schultz 2002). En particular, se estima que las orugas (larvas de mariposas, orden Lepidoptera) son los principales consumidores de follaje en los bosques tropicales, ingiriendo entre $2-5 \%$ de las hojas que se producen en ellos (D. Janzen, com. pers.). Más de 1600 especies de orugas se han estudiado en el Área de Conservación Guanacaste (ACG), en el noroeste de Costa Rica, tanto en su ambiente natural como en edificaciones diseñadas para 
su crianza, y su historia natural se ha documentado ampliamente (Janzen 1981，1984, 1985, 1993, 1997). Sin embargo, existe escasa información sobre la microbiota asociada al tracto digestivo de orugas tropicales (Sittenfeld et al. 2002, Broderick et al. 2004).

El intestino de orugas se caracteriza por un transporte epitelial muy activo, y el valor más alto de $\mathrm{pH}$ producido por un sistema biológico (Dow 1992). El elevado pH, la presencia de potenciales sustancias antimicrobianas secretadas por el insecto (Russell y Dunn 1991) o derivadas del tejido vegetal ingerido, la gran cantidad de alimento consumido y la alta competencia entre microorganismos sugieren que las bacterias capaces de proliferar en este hábitat podrían presentar adaptaciones para superar las condiciones adversas mencionadas. Algunas de dichas adaptaciones podrían basarse en la optimización de sus capacidades enzimáticas, logrando así un máximo aprovechamiento de los diversos sustratos disponibles. Estudios anteriores han demostrado la presencia de bacterias de diversos géneros en tractos digestivos de larvas y en material de pupas de A. zugana y en intestinos de Lymantria dispar L. (Sittenfeld et al. 2002, Broderick et al. 2004), aunque se desconocen las implicaciones de estos microorganismos en el desarrollo y mantenimiento del estadio pupal.

El análisis de las actividades enzimáticas presentes en la microbiota intestinal de orugas y del contenido de las pupas genera dos beneficios potenciales. Constituye un punto de partida para entender la contribución de la comunidad microbiana en el metabolismo y fisiología de larvas y pupas de lepidópteros. Además, permite identificar enzimas con características novedosas, que podrían ser utilizadas en procesos biotecnológicos o industriales. Cabe destacar que el elevado $\mathrm{pH}$ del tracto digestivo de orugas incrementa la posibilidad de identificar enzimas cuya actividad sea óptima a $\mathrm{pH}$ alcalino, requisito crucial en ciertos procesos industriales (Horikoshi 1999).

Las enzimas evaluadas en esta investigación han sido empleadas en diferentes procesos de importancia económica. Por ejemplo, las proteasas se utilizan en la elaboración de quesos y cueros y como aditivos de detergentes, las amilasas en procesamiento de almidón para obtener siropes y otros productos alimenticios y en la producción de papel y textiles, las celulasas para el aprovechamiento de desechos vegetales, las lipasas y esterasas como aditivos en detergentes, y las xilanasas son utilizadas en la fabricación de papel y en la industria panificadora (Horikoshi 1999, Christov et al. 1999, Lengeler et al. 1999, de Vries y Visser 2001). Por su parte, las quitinasas se han utilizado para obtener un beneficio energético de los desechos de la industria del camarón (Rojas-Avelizapa et al. 1999), en la industria alimentaria y farmacéutica (Hirano 1996) y en la protección de cultivos contra plagas agrícolas, pues inhiben el crecimiento de hongos fitopatógenos (Chernin et al. 1995, Chernin et al. 1997, Downing y Thompson 2000) y tienen un efecto sinérgico con las proteínas insecticidas Cry de Bacillus thuringiensis (Regev et al. 1996, Sampson y Gooday 1998, Downing et al. 2000).

El presente estudio pretende obtener información sobre enzimas secretadas por bacterias cultivables en aerobiosis, y los resultados servirán de referencia para investigaciones que utilicen técnicas moleculares independientes de cultivo (Rondon et al. 2000). Asimismo, este trabajo representa un punto de partida para estudiar el potencial biotecnológico de aislamientos bacterianos del tracto digestivo de orugas.

\section{MATERIALES Y MÉTODOS}

Aislamientos bacterianos de tractos digestivos y pupas de A. zugana: los aislamientos utilizados en este trabajo fueron obtenidos por Sittenfeld y colaboradores (2002). Brevemente, se recolectaron larvas de tercer estadio del lepidóptero A. zugana en el ACG, en junio de 1999 (estación lluviosa). El ACG esta localizado en Santa Rosa, entre el Golfo de Papagayo y la Carretera Interamericana $\left(10^{\circ} 44^{\prime} 13^{\prime \prime}-11^{\circ} 00^{\prime} 37^{\prime \prime} \mathrm{N}\right.$ y $\left.85^{\circ} 34^{\prime} 48^{\prime \prime}-85^{\circ} 58^{\prime} 51^{\prime \prime} \mathrm{W}\right)$. Los individuos fueron criados individualmente y alimentados con 
diferentes plantas hospederas (Annona purpurea, Cordia alliodora, Inga vera, Quercus oleoides, Paullinia cururu, Cydista heterophylla, Trigonia rugosa y Calycophyllum candidissimum), para determinar si el tipo de dieta ejercía alguna influencia sobre la microbiota intestinal. Las larvas de quinto estadio fueron sacrificadas de uno a tres días antes de entrar en la fase de pre-pupas. Sus tractos digestivos fueron disectados y cultivados en diferentes medios, tanto selectivos como de enriquecimiento, en aerobiosis. Los diferentes morfotipos coloniales obtenidos fueron identificados mediante pruebas bioquímicas tradicionales (Sittenfeld et al. 2002). También se procesaron ocho individuos en fase de pupas, en cuyo caso el contenido total de la pupa se trató de la misma manera que el intestino de las larvas. En total, se determinaron las actividades enzimáticas de 72 aislamientos bacterianos provenientes de muestras de A. zugana. De ellos, 48 fueron obtenidos a partir de 33 muestras de intestinos, mientras 24 se aislaron del contenido de las pupas procesadas.

Aislamientos bacterianos de tractos digestivos y pupas de $R$. lebeau: se analizaron las actividades enzimáticas de una colección de 81 aislamientos provenientes de intestinos de orugas y del material de pupas de $R$. lebeau (Fontecha 2002). Dicha colección proviene de ejemplares recolectados en el ACG durante los meses de junio a julio de 2001 (estación lluviosa). Brevemente, se disectaron los tractos digestivos de un total de 67 individuos de los cinco estadios larvales. Además, se procesó el contenido de diez pupas. Se efectuaron diluciones del material intestinal o del contenido de las pupas en solución salina isotónica, las cuales se sembraron en agar Luria-Bertani (LB) y se incubaron a $30{ }^{\circ} \mathrm{C}$ durante $48 \mathrm{~h}$ en aerobiosis. Los diferentes morfotipos coloniales seleccionados fueron identificados mediante el sistema semiautomatizado BIOLOG® (Biolog, Inc., Hayward, California, EEUU), según las instrucciones del fabricante. En total, se analizaron 64 aislamientos provenientes de intestinos de orugas y 17 aislamientos obtenidos de pupas.
Determinación de actividades enzimáticas: todos los aislamientos bacterianos previamente identificados fueron sembrados en placas de agar nutritivo e incubados a $30{ }^{\circ} \mathrm{C}$ durante 24 h. Se realizó una tinción de Gram a las colonias aisladas y con ellas se inocularon los medios de cultivo de los diferentes ensayos enzimáticos. Los ensayos fueron adaptados y modificados a partir de protocolos previamente descritos (Rondon et al. 1999, 2000, S. Amato, com. pers.). Todos los períodos de incubación se efectuaron a $30{ }^{\circ} \mathrm{C}$. Cada prueba contó con los controles correspondientes (positivo y negativo).

Actividad proteolítica/caseinolítica: se determinó inoculando cada aislamiento bacteriano en placas de agar Luria-Bertani (LB, Oxoid) suplementado con un volumen de leche descremada líquida comercial, equivalente a un gramo de leche en polvo por cada $100 \mathrm{ml}$ de medio de cultivo (aproximadamente $8 \mathrm{ml}$ de leche por cada $100 \mathrm{ml}$ de medio LB). La prueba se consideró positiva cuando se observó un halo claro alrededor de la colonia a las $48 \mathrm{~h}$ de incubación.

Actividades celulolítica y xilanolítica: se empleó como base un medio con $0.3 \%$ de extracto de levadura (Oxoid), $0.1 \%$ de $\left(\mathrm{NH}_{4}\right)_{2} \mathrm{SO}_{4}, 0.02 \%$ de $\mathrm{MgSO}_{4} .7 \mathrm{H}_{2} \mathrm{O}, 0.3 \%$ de una solución de elementos traza (McLellan et al. 1991) y $1.5 \%$ de agar (SIGMA, St. Louis, Missouri, EEUU), disueltos en buffer de fosfatos $0.01 \mathrm{M} \mathrm{pH} \mathrm{7.0.} \mathrm{Al} \mathrm{medio} \mathrm{base} \mathrm{se} \mathrm{agregó}$ celulosa en polvo al $1 \%$ (ICN Biomedicals, Aurora, Ohio, EEUU) o xilano al $1 \%$ (ICN Biomedicals). Los aislamientos bacterianos se inocularon en este medio y se incubaron por 48 h. Para revelar la prueba, se agregaron $2 \mathrm{ml} \mathrm{de}$ reactivo de Graff " $\mathrm{C}$ " $\left(16 \% \mathrm{AlCl}_{3} \cdot 6 \mathrm{H}_{2} \mathrm{O}, 13\right.$ $\% \mathrm{CaCl}_{2}, 40 \% \mathrm{ZnCl}_{2}, 0.7 \% \mathrm{I}_{2}$ y $\left.0.5 \% \mathrm{KI}\right)$, siendo positiva si se producía un halo claro alrededor del crecimiento bacteriano, en un entorno violáceo.

Actividad esterásica: se valoró inoculando los aislamientos bacterianos en platos de agar LB suplementados con Tween 20 al $1 \%$ 
(SIGMA). La prueba se consideró positiva al observar un halo granular alrededor del crecimiento bacteriano, luego de un período de incubación de $96 \mathrm{~h}$.

Actividad lipolítica: los aislamientos bacterianos se inocularon en caldo nutritivo y se incubaron por $24 \mathrm{~h}$, luego $20 \mu \mathrm{l}$ de cada cultivo se inocularon en una solución con Tween 80 al $0.5 \%$ (Sigma) y rojo neutro $0.1 \mathrm{~m} / \mathrm{v}$ al $2 \%$ (ICN Biomedicals) disueltos en buffer de fosfatos $0.067 \mathrm{M}, \mathrm{pH}$ 7.0. La prueba se consideró positiva si antes de cinco días la solución adquirió color rojo.

Actividad proteolítica/gelatinolítica: se evaluó inoculando los aislamientos bacterianos en tubos de gelatina nutritiva (Oxoid) e incubándolos por $96 \mathrm{~h}$. Los aislamientos activos hidrolizan la gelatina, impidiendo la solidificación del medio luego de $15 \min$ a $4{ }^{\circ} \mathrm{C}$.

Actividad amilásica: se detectó inoculando los aislamientos bacterianos en placas de agar LB suplementados con almidón al $1 \%$ (ICN Biomedicals). Luego de $48 \mathrm{~h}$ de incubación se agregó reactivo de lugol. El ensayo se consideró positivo al observarse un halo claro alrededor o bajo la colonia luego de agregar el reactivo mencionado.

Actividad quitinolítica: se empleó como base el medio de Castañeda (Castañeda-Agulló 1956): $0.06 \%\left(\mathrm{NH}_{4}\right)_{2} \mathrm{HC}_{6} \mathrm{H}_{5} \mathrm{O}_{7}, 0.02 \% \mathrm{NaCl}$, $0.04 \% \mathrm{KH}_{2} \mathrm{PO}_{4}, 0.01 \% \mathrm{MgSO}_{4} .7 \mathrm{H}_{2} \mathrm{O}$ y 0.04 $\%$ de $\mathrm{Na}_{2} \mathrm{CO}_{3}$. Dicho medio fue suplementado con agar (SIGMA) y con quitina coloidal al 13 $\%$ (preparada a partir de quitina grado práctico (SIGMA) mediante tratamiento con $\mathrm{H}_{3} \mathrm{PO}_{4}$ concentrado). Cada aislamiento bacteriano fue inoculado en este medio sólido. La prueba se consideró positiva al observarse un halo claro alrededor del crecimiento bacteriano, luego de una semana de incubación.

Construcción de árboles fenotípicos: para agrupar a los aislamientos bacterianos evaluados de acuerdo con sus actividades enzimáticas, se construyeron árboles fenotípicos empleando el programa "Treecon", versión $1.3 \mathrm{~b}$ y la distancia fue estimada utilizando el método de Nei y Li (Van de Peer y De Wachter 1994). El árbol se construyó por medio de una adaptación del método de Neighbor-Joining (Hershkovitz y Leipe 1998), con un análisis de re-muestreo (bootstrap) de 100 muestras. Para cada aislamiento bacteriano, se asignó un valor de 0 ó 1 a cada prueba enzimática realizada, según esta produjese un resultado negativo o positivo, respectivamente, y la matriz obtenida se procesó en el paquete informático mencionado, eligiendo la opción que corresponde al análisis de patrones de RFLP. Los árboles construidos se basan en características fenotípicas, por lo que no reflejan relaciones filogenéticas entre los organismos involucrados. En todos los casos se utilizó como grupo externo el aislamiento A363 correspondiente a Bacillus sp., el cual proviene del material de una pupa de $A$. zugana y posee un patrón enzimático único: solamente presenta actividad xilanolítica.

\section{RESULTADOS}

Actividades enzimáticas en aislamientos bacterianos de $A$. zugana: los 72 aislamientos obtenidos de A. zugana fueron agrupados en cuatro categorías: bacterias de las familias Enterobacteriaceae y Pseudomonadaceae, cocos Gram-positivos y bacilos Gram-positivos. Los resultados de los ensayos enzimáticos para estos aislamientos se presentan en el Cuadro 1. En general, los aislamientos de intestinos mostraron un comportamiento enzimático similar al de sus homólogos provenientes de pupas. Ninguna de las bacterias estudiadas produjo un resultado positivo en todos los ensayos enzimáticos, sin embargo, la totalidad de la colección de aislamientos de A. zugana sí fue capaz de utilizar todos los sustratos probados. En varias ocasiones, aislamientos con la misma identificación taxonómica presentaron un patrón enzimático distinto. Cuatro aislamientos identificados como Bacillus thuringiensis 
CUADRO 1

Actividades enzimáticas de aislamientos bacterianos obtenidos de intestinos de larvas $y$ del contenido de pupas del lepidóptero A. zugana

TABLE 1

Enzymatic activities of bacterial isolates from digestive tracts of caterpillars and pupal contents of A. zugana

\begin{tabular}{|c|c|c|c|c|c|c|c|c|c|}
\hline \multirow{2}{*}{ Identificación } & \multirow{2}{*}{ Origen $^{\mathrm{a}}$} & \multicolumn{8}{|c|}{ Aislamientos con actividad / Aislamientos evaluados } \\
\hline & & GEL. & CAS. & LIP. & EST. & QUI. & AMI. & CEL. & XIL. \\
\hline Enterobacteriaceae & $\mathrm{I}, \mathrm{P}$ & $24 / 31$ & $23 / 31$ & $26 / 31$ & $25 / 31$ & $21 / 31$ & $1 / 31$ & $1 / 31$ & $1 / 31$ \\
\hline Citrobacter freundii & I & $1 / 1$ & $1 / 1$ & $1 / 1$ & $1 / 1$ & $1 / 1$ & $0 / 1$ & $0 / 1$ & $0 / 1$ \\
\hline Enterobacter aerogenes & I & $1 / 1$ & $1 / 1$ & $1 / 1$ & $1 / 1$ & $1 / 1$ & $0 / 1$ & $0 / 1$ & $0 / 1$ \\
\hline Enterobacter agglomerans & I & $1 / 1$ & $1 / 1$ & $1 / 1$ & $0 / 1$ & $0 / 1$ & $0 / 1$ & $0 / 1$ & $0 / 1$ \\
\hline E. agglomerans / cloacae & I & $1 / 1$ & $1 / 1$ & $1 / 1$ & $1 / 1$ & $1 / 1$ & $0 / 1$ & $0 / 1$ & $0 / 1$ \\
\hline Enterobacter cloacae & I & $2 / 5$ & $2 / 5$ & $3 / 5$ & $4 / 5$ & $1 / 5$ & $0 / 5$ & $0 / 5$ & $0 / 5$ \\
\hline Enterobacter gergoviae & I & $4 / 4$ & $3 / 4$ & $3 / 4$ & $3 / 4$ & $3 / 4$ & $0 / 4$ & $0 / 4$ & $0 / 4$ \\
\hline Enterobacter sp. ${ }^{\mathrm{b}}$ & I & $3 / 6$ & $3 / 6$ & $4 / 6$ & $3 / 6$ & $3 / 6$ & $1 / 6$ & $1 / 6$ & $1 / 6$ \\
\hline Enterobacter sp. & $\mathrm{P}$ & $3 / 4$ & $3 / 4$ & $4 / 4$ & $4 / 4$ & $3 / 4$ & $0 / 4$ & $0 / 4$ & $0 / 4$ \\
\hline Klebsiella pneumoniae & I & $1 / 1$ & $1 / 1$ & $1 / 1$ & $1 / 1$ & $1 / 1$ & $0 / 1$ & $0 / 1$ & $0 / 1$ \\
\hline Serratia marcesens & I & $2 / 2$ & $2 / 2$ & $2 / 2$ & $2 / 2$ & $2 / 2$ & $0 / 2$ & $0 / 2$ & $0 / 2$ \\
\hline S. marcesens & $\mathrm{P}$ & $4 / 4$ & $4 / 4$ & $4 / 4$ & $4 / 4$ & $4 / 4$ & $0 / 4$ & $0 / 4$ & $0 / 4$ \\
\hline Serratia sp. & I & $1 / 1$ & $1 / 1$ & $1 / 1$ & $1 / 1$ & $1 / 1$ & $0 / 1$ & $0 / 1$ & $0 / 1$ \\
\hline Pseudomonadaceae & $\mathrm{I}, \mathrm{P}$ & $1 / 11$ & $1 / 11$ & $1 / 11$ & $3 / 11$ & $0 / 11$ & $0 / 11$ & $0 / 11$ & $0 / 11$ \\
\hline Pseudomonas diminuta & I & $0 / 1$ & $0 / 1$ & $0 / 1$ & $0 / 1$ & $0 / 1$ & $0 / 1$ & $0 / 1$ & $0 / 1$ \\
\hline P. diminuta & $P$ & $0 / 3$ & $0 / 3$ & $1 / 3$ & $0 / 3$ & $0 / 3$ & $0 / 3$ & $0 / 3$ & $0 / 3$ \\
\hline P. mallei & $\mathrm{P}$ & $0 / 3$ & $1 / 3$ & $0 / 3$ & $3 / 3$ & $0 / 3$ & $0 / 3$ & $0 / 3$ & $0 / 3$ \\
\hline Pseudomonas sp. & I & $1 / 1$ & $0 / 1$ & $0 / 1$ & $0 / 1$ & $0 / 1$ & $0 / 1$ & $0 / 1$ & $0 / 1$ \\
\hline Pseudomonas sp. & $\mathrm{P}$ & $0 / 2$ & $0 / 2$ & $0 / 2$ & $0 / 2$ & $0 / 2$ & $0 / 2$ & $0 / 2$ & $0 / 2$ \\
\hline P. syringue & $\mathrm{P}$ & $0 / 1$ & $0 / 1$ & $0 / 1$ & $0 / 1$ & $0 / 1$ & $0 / 1$ & $0 / 1$ & $0 / 1$ \\
\hline Cocos Gram-positivos & $\mathrm{I}, \mathrm{P}$ & $10 / 15$ & $11 / 15$ & $1 / 15$ & $0 / 15$ & $0 / 15$ & $3 / 15$ & $5 / 15$ & $5 / 15$ \\
\hline Staphylococcus aureus & I & $1 / 1$ & $1 / 1$ & $0 / 1$ & $0 / 1$ & $0 / 1$ & $0 / 1$ & $0 / 1$ & $0 / 1$ \\
\hline Staphylococcus sp. & I & $2 / 4$ & $3 / 4$ & $0 / 4$ & $0 / 4$ & $0 / 4$ & $0 / 4$ & $0 / 4$ & $0 / 4$ \\
\hline Staphylococcus sp. & $\mathrm{P}$ & $1 / 1$ & $1 / 1$ & $0 / 1$ & $0 / 1$ & $0 / 1$ & $0 / 1$ & $0 / 1$ & $0 / 1$ \\
\hline Micrococcus sp. & I & $3 / 3$ & $3 / 3$ & $0 / 3$ & $0 / 3$ & $0 / 3$ & $0 / 3$ & $0 / 3$ & $0 / 3$ \\
\hline Leuconostoc citreum & I & $3 / 5$ & $3 / 5$ & $1 / 5$ & $0 / 5$ & $0 / 5$ & $2 / 5$ & $4 / 5$ & $4 / 5$ \\
\hline L. citreum & $\mathrm{P}$ & $0 / 1$ & $0 / 1$ & $0 / 1$ & $0 / 1$ & $0 / 1$ & $1 / 1$ & $1 / 1$ & $1 / 1$ \\
\hline Bacilos Gram-positivos & $\mathrm{I}, \mathrm{P}$ & $10 / 15$ & $10 / 15$ & $2 / 15$ & $7 / 15$ & $2 / 15$ & $10 / 15$ & $10 / 15$ & $11 / 15$ \\
\hline Bacillus sp. & $\mathrm{P}$ & $0 / 2$ & $0 / 2$ & $0 / 2$ & $0 / 2$ & $1 / 2$ & $1 / 2$ & $1 / 2$ & $2 / 2$ \\
\hline B. mascerans & $\mathrm{P}$ & $0 / 1$ & $0 / 1$ & $0 / 1$ & $1 / 1$ & $0 / 1$ & $1 / 1$ & $1 / 1$ & $1 / 1$ \\
\hline Bacillus thuringiensis & I & $7 / 7$ & $7 / 7$ & $0 / 7$ & $4 / 7$ & $0 / 7$ & $7 / 7$ & $7 / 7$ & $7 / 7$ \\
\hline Corynebacterium pyogenes & I & $0 / 1$ & $0 / 1$ & $0 / 1$ & $1 / 1$ & $0 / 1$ & $0 / 1$ & $0 / 1$ & $0 / 1$ \\
\hline Listeria monocytogenes & I & $0 / 1$ & $0 / 1$ & $0 / 1$ & $1 / 1$ & $1 / 1$ & $1 / 1$ & $1 / 1$ & $1 / 1$ \\
\hline Curtobacterium sp. & I & $1 / 1$ & $1 / 1$ & $1 / 1$ & $0 / 1$ & $0 / 1$ & $0 / 1$ & $0 / 1$ & $0 / 1$ \\
\hline Curtobacterium sp. & $\mathrm{P}$ & $2 / 2$ & $2 / 2$ & $1 / 2$ & $0 / 2$ & $0 / 2$ & $0 / 2$ & $0 / 2$ & $0 / 2$ \\
\hline TOTAL & $\mathrm{I}, \mathrm{P}$ & $45 / 72$ & $45 / 72$ & $30 / 72$ & $35 / 72$ & $23 / 72$ & $14 / 72$ & $16 / 72$ & $17 / 72$ \\
\hline
\end{tabular}

a. Origen de los aislamientos: $\mathrm{I}$ = intestinos de larvas; $\mathrm{P}=$ contenido de pupas.

b. Identificación de especie no fue posible con la metodología empleada en el correspondiente estudio.

$\mathrm{GEL}=$ actividad gelatinolítica, $\mathrm{CAS}=$ caseinolítica, $\mathrm{LIP}=$ lipolítica, $\mathrm{EST}=$ esterásica, $\mathrm{QUI}=$ quitinolítica, $\mathrm{AMI}=\mathrm{amilásica}$, $\mathrm{CEL}=$ celulolítica, $\mathrm{XIL}=$ xilanolítica. 
presentaron el mayor número de actividades enzimáticas (seis de las ocho evaluadas).

Las actividades más frecuentes en la colección fueron caseinolítica y gelatinolítica. Ambas se observan en el $62.5 \%$ de los aislamientos bacterianos y ocurren tanto en bacterias Gram-positivas como Gram-negativas. Por otro lado, las actividades menos frecuentes fueron quitinolítica (31.9\%), xilanolítica (23.6\%), celulolítica (22.2\%) y amilásica (19.4\%). Las actividades lipolítica y esterásica se detectaron en el $41.7 \%$ y en el $48.6 \%$ de los aislamientos, respectivamente (Cuadro 1). Cabe destacar que la actividades amilásica, celulolítica y xilanolítica se observan casi exclusivamente en bacterias Gram-positivas, mientras las actividades quitinolítica y lipolítica se circunscriben casi por completo a aislamientos de la familia Enterobacteriaceae. Ningún aislamiento de dicha familia mostró actividad quitinolítica y celulolítica simultáneamente. Los aislamientos de la familia Pseudomonadaceae, obtenidos principalmente de pupas, mostraron un bajo porcentaje de actividad en los diferentes ensayos.

En el árbol fenotípico construido para la colección de aislamientos de A. zugana (Fig. 1) se pueden distinguir tres grupos bien definidos de acuerdo con su patrón de actividades enzimáticas. El primero, en la parte superior del árbol (aislamientos A621a hasta A701), está formado exclusivamente por aislamientos de la familia Enterobacteriaceae. Este grupo tiene un alto porcentaje de positividad en las actividades caseinolítica, gelatinolítica, lipolítica, esterásica y quitinolítica, pero carece de las restantes. El segundo grupo, en el centro del árbol (aislamientos A621b a A63p1), está conformado por aislamientos poco activos, con solamente dos, una o ninguna actividad enzimática. En él se ubican todos los 11 aislamientos de la familia Pseudomonaceae, algunos de Enterobacteriaceae $(n=7)$, la mayoría de los cocos Gram-positivos (excepto los aislamientos del género Leuconostoc) y tres bacilos Grampositivos. El tercer grupo, en la parte inferior del árbol (aislamientos A773a hasta A721), está compuesto por la mayoría de bacilos Grampositivos, incluyendo todos los aislamientos de
B. thuringiensis, cinco aislamientos del género Leuconostoc y solamente una enterobacteria. Ellos comparten al menos la presencia de dos de las siguientes tres actividades: xilanolítica, amilásica o celulolítica. En general, este grupo se distingue por un alto porcentaje de positividad en las pruebas de actividad caseinolítica, gelatinolítica, amilásica, celulolítica y xilanolítica, en tanto la actividad esterásica es variable, y las actividades lipolítica y quitinolítica están ausentes. Nótese además como los aislamientos provenientes de pupas (distinguibles por la letra "P" al final de su código de identificación) fueron agrupados junto a sus homólogos provenientes de intestinos de orugas.

\section{Actividades enzimáticas en aislamientos} bacterianos de $R$. lebeau: los resultados de los ensayos enzimáticos realizados en 81 aislamientos bacterianos provenientes de tractos digestivos y pupas de $R$. lebeau se resumen en el Cuadro 2. Al igual que las bacterias obtenidas de A. zugana, los aislamientos se dividieron en cuatro categorías, aunque en este caso el grupo de la familia Pseudomonadaceae es sustituido por aislamientos de bacilos Gram-negativos que no pertenecen a la familia Enterobacteriaceae. Al igual que en A. zugana, se obtuvieron aislamientos con la misma identificación taxonómica que mostraron un patrón enzimático distinto. De igual modo, es notorio que los aislamientos obtenidos de pupas muestran un comportamiento enzimático similar al de sus homólogos provenientes de intestinos de orugas. Las actividades enzimáticas más frecuentes fueron gelatinolítica (presente en $56.8 \%$ de los aislamientos) y caseinolítica $(53.1 \%)$, seguidas por las actividades esterásica $(44.4 \%)$, xilanolítica (42\%), celulolítica (37.0\%) y lipolítica (35.8 \%). La actividad quitinolítica se observa sólo en el $16.0 \%$ de los aislamientos, mientras la actividad amilásica estuvo presente solamente en el $23.5 \%$ de los mismos. Dos aislamientos identificados como Curtobacterium pusilum presentaron siete actividades enzimáticas (solamente carecían de actividad quitinolítica), siendo los más activos de esta colección. Aunque ninguna bacteria 


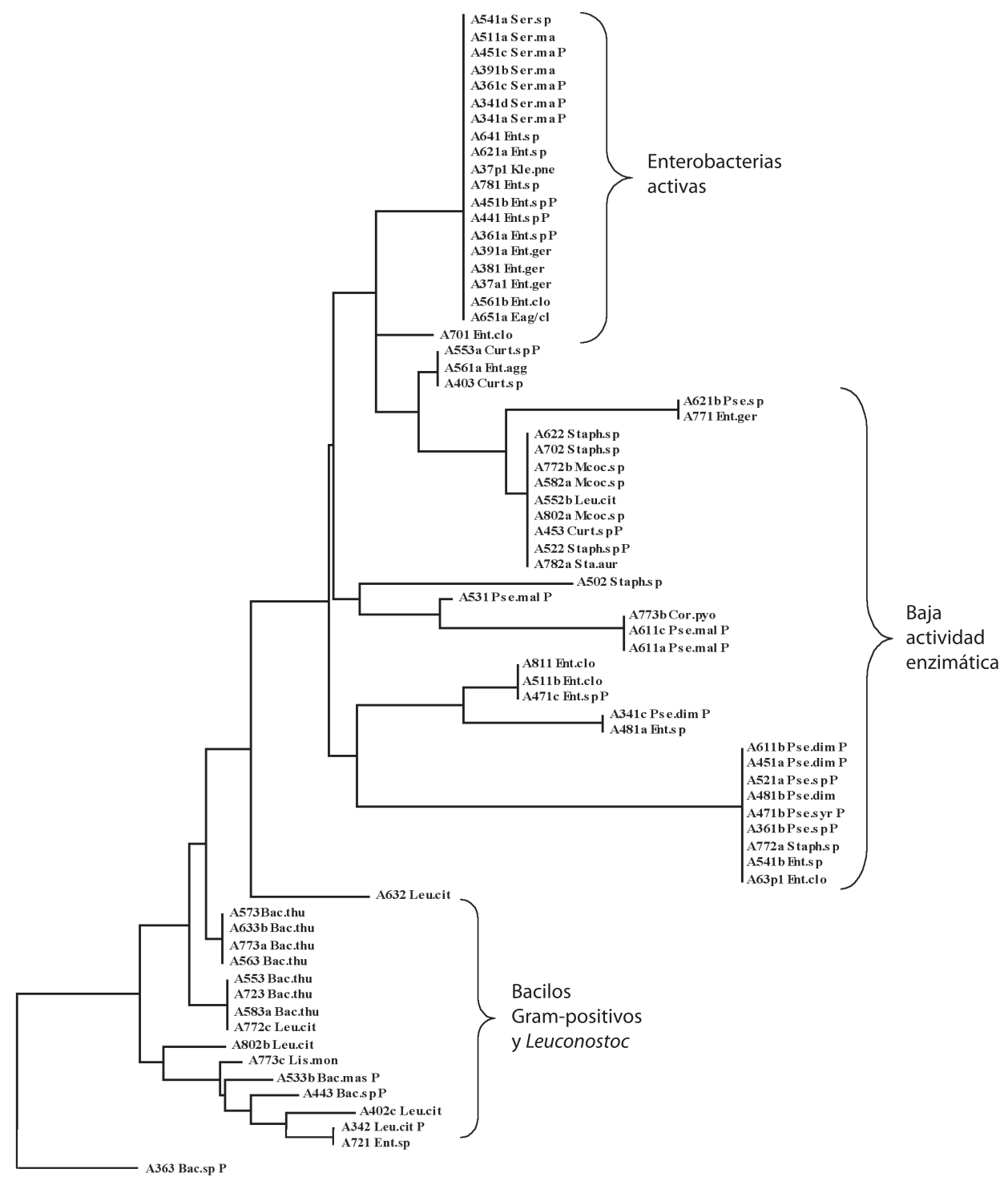

Fig. 1. Agrupamiento de los aislamientos bacterianos provenientes de A. zugana de acuerdo con sus actividades enzimáticas. El árbol fue construido empleando el programa informático Treecon para Windows, versión 1.3b (Van de Peer y de Wachter 1994), usando el método de Neighbor-Joining. Para cada aislamiento, se asignó un valor de 1 ó 0 para cada ensayo enzimático, según este fuese positivo o negativo. La matriz obtenida se procesó según las indicaciones del programa informático. Más detalles sobre la construcción del árbol se hallan en la sección de materiales y métodos. Aislamientos obtenidos del contenido de pupas poseen una letra "P" al final de su código de identificación. Este es un árbol fenotípico basado en actividades enzimáticas y no refleja necesariamente relaciones filogenéticas entre los aislamientos evaluados. Ver texto para interpretación de los resultados.

Fig. 1. Grouping of bacterial isolates obtained from A. zugana according to their enzymatic activities. The tree was constructed employing the software Treecon for Windows, version 1.3b (Van de Peer and de Wachter 1994), using the NeighborJoining algorithm. For each isolate, a value of 1 or 0 was assigned for each enzymatic test, depending on whether the test was positive or negative. The obtained matrix was processed according to the instructions of the Treecon software. For more details on the construction of the tree, see materials and methods. Isolates obtained from pupae samples are labeled with a letter "P" after their identification code. This is a phenotypic tree based on enzymatic activities and does not reflect necessarily phylogenetic relationships between the isolates evaluated. See text for interpretation of the obtained results. 
CUADRO 2

Actividades enzimáticas de aislamientos bacterianos obtenidos de intestinos de larvas y del contenido de pupas del lepidóptero R. lebeau

TABLE 2

Enzymatic activities of bacterial isolates from digestive tracts of caterpillars and pupal contents of $\mathrm{R}$. lebeau

\begin{tabular}{|c|c|c|c|c|c|c|c|c|c|}
\hline \multirow{2}{*}{ Identificación } & \multirow{2}{*}{ Origen $^{\mathrm{a}}$} & \multicolumn{8}{|c|}{ Aislamientos con actividad / Aislamientos evaluados } \\
\hline & & GEL. & CAS. & LIP. & EST. & QUI. & AMI. & CEL. & XIL. \\
\hline Enterobacteriaceae & $\mathrm{P}, \mathrm{I}$ & $19 / 25$ & $15 / 25$ & $17 / 25$ & $19 / 25$ & $12 / 25$ & $0 / 25$ & $0 / 25$ & $2 / 25$ \\
\hline Enterobacter cloacae & I & $0 / 1$ & $0 / 1$ & $0 / 1$ & $0 / 1$ & $0 / 1$ & $0 / 1$ & $0 / 1$ & $0 / 1$ \\
\hline Klebsiella planticola & I & $1 / 1$ & $1 / 1$ & $1 / 1$ & $1 / 1$ & $1 / 1$ & $0 / 1$ & $0 / 1$ & $0 / 1$ \\
\hline Klebsiella terrigena & I & $1 / 1$ & $0 / 1$ & $0 / 1$ & $0 / 1$ & $0 / 1$ & $0 / 1$ & $0 / 1$ & $1 / 1$ \\
\hline K. terrigena & $\mathrm{P}$ & $0 / 1$ & $0 / 1$ & $0 / 1$ & $1 / 1$ & $0 / 1$ & $0 / 1$ & $0 / 1$ & $0 / 1$ \\
\hline Morganella morganii & I & $0 / 2$ & $0 / 2$ & $1 / 2$ & $1 / 2$ & $0 / 2$ & $0 / 2$ & $0 / 2$ & $0 / 2$ \\
\hline Pantoea dispersa & I & $2 / 4$ & $0 / 4$ & $1 / 4$ & $1 / 4$ & $0 / 4$ & $0 / 4$ & $0 / 4$ & $1 / 4$ \\
\hline Proteus mirabilis & I & $1 / 1$ & $0 / 1$ & $1 / 1$ & $1 / 1$ & $1 / 1$ & $0 / 1$ & $0 / 1$ & $0 / 1$ \\
\hline Serratia marcesens & I & $14 / 14$ & $14 / 14$ & $13 / 14$ & $14 / 14$ & $10 / 14$ & $0 / 14$ & $0 / 14$ & $0 / 14$ \\
\hline Gram-neg. no entéricos & $\mathrm{P}, \mathrm{I}$ & $5 / 10$ & $2 / 10$ & $5 / 10$ & $6 / 10$ & $1 / 10$ & $4 / 10$ & $4 / 10$ & $4 / 10$ \\
\hline Agrobacterium rhizogenes & I & $1 / 1$ & $0 / 1$ & $0 / 1$ & $1 / 1$ & $0 / 1$ & $1 / 1$ & $0 / 1$ & $1 / 1$ \\
\hline Brevundimonas diminuta & $\mathrm{P}$ & $1 / 2$ & $0 / 2$ & $2 / 2$ & $2 / 2$ & $0 / 2$ & $0 / 2$ & $1 / 2$ & $0 / 2$ \\
\hline Comamonas terrigena & $\mathrm{P}$ & $0 / 1$ & $0 / 1$ & $0 / 1$ & $0 / 1$ & $0 / 1$ & $0 / 1$ & $0 / 1$ & $0 / 1$ \\
\hline Pseudomonas sp. ${ }^{\mathrm{b}}$ & I & $2 / 2$ & $1 / 2$ & $2 / 2$ & $2 / 2$ & $1 / 2$ & $0 / 2$ & $0 / 2$ & $0 / 2$ \\
\hline Pseudomonas sp. & $\mathrm{P}$ & $0 / 1$ & $0 / 1$ & $1 / 1$ & $1 / 1$ & $0 / 1$ & $1 / 1$ & $0 / 1$ & $0 / 1$ \\
\hline P. maculicula & $\mathrm{P}$ & $0 / 1$ & $0 / 1$ & $0 / 1$ & $0 / 1$ & $0 / 1$ & $1 / 1$ & $1 / 1$ & $1 / 1$ \\
\hline P. stutzeri & I & $1 / 1$ & $1 / 1$ & $0 / 1$ & $0 / 1$ & $0 / 1$ & $0 / 1$ & $1 / 1$ & $1 / 1$ \\
\hline P. stutzeri & $\mathrm{P}$ & $0 / 1$ & $0 / 1$ & $0 / 1$ & $0 / 1$ & $0 / 1$ & $1 / 1$ & $1 / 1$ & $1 / 1$ \\
\hline Cocos Gram-positivos & $\mathrm{P}, \mathrm{I}$ & $7 / 21$ & $7 / 21$ & $1 / 21$ & $3 / 21$ & $0 / 21$ & $2 / 21$ & $7 / 21$ & $6 / 21$ \\
\hline Micrococcus luteus & I & $1 / 1$ & $1 / 1$ & $0 / 1$ & $0 / 1$ & $0 / 1$ & $0 / 1$ & $1 / 1$ & $1 / 1$ \\
\hline Staphylococcus sp. & I & $1 / 2$ & $2 / 2$ & $1 / 2$ & $0 / 2$ & $0 / 2$ & $0 / 2$ & $2 / 2$ & $2 / 2$ \\
\hline S. arlettae & I & $1 / 3$ & $0 / 3$ & $0 / 3$ & $1 / 3$ & $0 / 3$ & $0 / 3$ & $0 / 3$ & $0 / 3$ \\
\hline S. arlettae & $\mathrm{P}$ & $1 / 2$ & $0 / 2$ & $0 / 2$ & $0 / 2$ & $0 / 2$ & $0 / 2$ & $0 / 2$ & $0 / 2$ \\
\hline S. aureus & I & $1 / 2$ & $2 / 2$ & $0 / 2$ & $1 / 2$ & $0 / 2$ & $0 / 2$ & $1 / 2$ & $0 / 2$ \\
\hline S. equorum & $\mathrm{P}$ & $1 / 1$ & $0 / 1$ & $0 / 1$ & $0 / 1$ & $0 / 1$ & $0 / 1$ & $0 / 1$ & $0 / 1$ \\
\hline S. haemolyticus & I & $0 / 2$ & $0 / 2$ & $0 / 2$ & $0 / 2$ & $0 / 2$ & $0 / 2$ & $1 / 2$ & $1 / 2$ \\
\hline S. haemolyticus & $\mathrm{P}$ & $0 / 2$ & $1 / 2$ & $0 / 2$ & $0 / 2$ & $0 / 2$ & $0 / 2$ & $0 / 2$ & $0 / 2$ \\
\hline S. lentus & I & $0 / 2$ & $1 / 2$ & $0 / 2$ & $0 / 2$ & $0 / 2$ & $2 / 2$ & $2 / 2$ & $2 / 2$ \\
\hline S. lentus & $\mathrm{P}$ & $0 / 2$ & $0 / 2$ & $0 / 2$ & $1 / 2$ & $0 / 2$ & $0 / 2$ & $0 / 2$ & $0 / 2$ \\
\hline S. saprophyticus & I & $1 / 1$ & $0 / 1$ & $0 / 1$ & $0 / 1$ & $0 / 1$ & $0 / 1$ & $0 / 1$ & $0 / 1$ \\
\hline S. suarezii & I & $0 / 1$ & $0 / 1$ & $0 / 1$ & $0 / 1$ & $0 / 1$ & $0 / 1$ & $0 / 1$ & $0 / 1$ \\
\hline Bacilos Gram-positivos & $\mathrm{P}, \mathrm{I}$ & $15 / 25$ & $19 / 25$ & $6 / 25$ & $8 / 25$ & $0 / 25$ & $13 / 25$ & $19 / 25$ & $22 / 25$ \\
\hline Aureobacterium testaceum & I & $0 / 1$ & $0 / 1$ & $0 / 1$ & $0 / 1$ & $0 / 1$ & $0 / 1$ & $1 / 1$ & $1 / 1$ \\
\hline Bacillus amyloliquefaciens & I & $1 / 1$ & $1 / 1$ & $1 / 1$ & $0 / 1$ & $0 / 1$ & $1 / 1$ & $1 / 1$ & $1 / 1$ \\
\hline B. cereus/thuringiensis & I & $1 / 1$ & $1 / 1$ & $0 / 1$ & $1 / 1$ & $0 / 1$ & $1 / 1$ & $1 / 1$ & $1 / 1$ \\
\hline B. megaterium & I & $1 / 1$ & $1 / 1$ & $0 / 1$ & $0 / 1$ & $0 / 1$ & $1 / 1$ & $1 / 1$ & $1 / 1$ \\
\hline B. subtilis & I & $0 / 1$ & $1 / 1$ & $0 / 1$ & $0 / 1$ & $0 / 1$ & $1 / 1$ & $1 / 1$ & $1 / 1$ \\
\hline B. subtilis & $\mathrm{P}$ & $1 / 1$ & $1 / 1$ & $0 / 1$ & $0 / 1$ & $0 / 1$ & $0 / 1$ & $0 / 1$ & $0 / 1$ \\
\hline Carnobacterium divergens & I & $0 / 1$ & $0 / 1$ & $0 / 1$ & $0 / 1$ & $0 / 1$ & $0 / 1$ & $1 / 1$ & $1 / 1$ \\
\hline Curtobacterium albidum & I & $3 / 6$ & $6 / 6$ & $0 / 6$ & $3 / 6$ & $0 / 6$ & $2 / 6$ & $4 / 6$ & $5 / 6$ \\
\hline C. citreum & I & $1 / 1$ & $1 / 1$ & $1 / 1$ & $0 / 1$ & $0 / 1$ & $1 / 1$ & $1 / 1$ & $1 / 1$ \\
\hline C. pusillum & I & $4 / 5$ & $4 / 5$ & $2 / 5$ & $3 / 5$ & $0 / 5$ & $3 / 5$ & $4 / 5$ & $5 / 5$ \\
\hline C. pusillum & $\mathrm{P}$ & $1 / 2$ & $0 / 2$ & $1 / 2$ & $0 / 2$ & $0 / 2$ & $2 / 2$ & $2 / 2$ & $2 / 2$ \\
\hline Microbacterium laevaniformans & I & $2 / 4$ & $3 / 4$ & $1 / 4$ & $1 / 4$ & $0 / 4$ & $1 / 4$ & $2 / 4$ & $3 / 4$ \\
\hline TOTAL & $\mathrm{P}, \mathrm{I}$ & $46 / 81$ & $43 / 81$ & $29 / 81$ & $36 / 81$ & $13 / 81$ & $19 / 81$ & $30 / 81$ & $34 / 81$ \\
\hline
\end{tabular}

a., b. Ver leyenda de cuadro 1. 
presentó todas las actividades evaluadas, sí se obtuvieron aislamientos positivos en cada una de las pruebas.

En esta colección también se observa que la actividad quitinolítica es casi exclusiva de aislamientos de la familia Enterobacteriaceae, los cuales no demostraron las actividades xilanolítica, celulolítica y amilásica. Estas tres últimas actividades se presentan principalmente en bacterias Gram-positivas, que a su vez carecen de actividad quitinolítica. Por otra parte, los aislamientos que pertenecen a la categoría de cocos Gram-positivos fueron los que mostraron menor porcentaje de actividad enzimática (Cuadro 2).

El árbol fenotípico construido para la colección de aislamientos de $R$. lebeau muestra un agrupamiento semejante al observado con A. zugana, aunque menos homogéneo (Fig. 2). En ambos se mantienen los mismos tres grupos principales. El primero, en la parte superior del árbol (aislamientos R67 a R128) está formado por aislamientos de la familia Enterobacteriaceae con al menos cuatro actividades enzimáticas, incluyendo lipolítica y/o quitinolítica y excluyendo xilanolítica, amilásica y celulolítica. El segundo grupo, en el centro del árbol (aislamientos R183 a R63), corresponde a aislamientos poco activos, en su mayoría con dos o menos actividades enzimáticas y es muy heterogéneo en cuanto a su composición, incluyendo aislamientos de las cuatro categorías antes mencionadas. El tercer grupo, en la parte inferior (aislamientos R75 a R190) está compuesto por aislamientos que comparten al menos dos de las siguientes tres actividades: xilanolítica, amilásica o celulolítica, y carecen de actividad quitinolítica. Está conformado principalmente por bacilos Gram-positivos, y en menor grado por cocos Gram-positivos y bacilos Gram-negativos no entéricos.

\section{DISCUSIÓN}

Se observó que los aislamientos bacterianos obtenidos de intestinos de larvas y pupas de lepidópteros son capaces de utilizar una gran variedad de sustratos diferentes bajo las condiciones experimentales de este estudio. $\mathrm{Si}$ bien es cierto ninguno de los aislamientos estudiados fue capaz de degradar todos los sustratos analizados, el conjunto de todos los aislamientos si generó resultados positivos en todas las ocho pruebas efectuadas. La presencia de estos microorganismos en el tracto digestivo podría incrementar la capacidad alimenticia de la oruga, pues se ha demostrado que compuestos intermedios producidos por bacterias a partir de sustratos más complejos pueden servir de alimento al insecto hospedero (Brune 1998).

Los aislamientos de pupas presentan un comportamiento enzimático semejante al de sus homólogos provenientes de intestinos. El papel de estos aislamientos en este microambiente y su participación en la fisiología de las pupas permanece como incógnita.

A pesar de las diferencias en cuanto a tipo de muestra analizada y metodología de identificación entre las colecciones analizadas, se logra observar un comportamiento enzimático similar para el conjunto de aislamientos bacterianos provenientes de orugas. En ambas poblaciones existen dos subgrupos que se distinguen de acuerdo con su patrón de secreción de enzimas (Fig. 3). Por un lado, la mayoría de aislamientos de la familia Enterobacteriaceae presentaron un alto porcentaje de actividad lipolítica y quitinolítica, pero no muestran actividad amilásica, celulolítica y xilanolítica. Exactamente lo contrario sucede con los bacilos Gram-positivos como B. thuringiensis. Los árboles fenotípicos construidos permiten corroborar las similitudes en el comportamiento enzimático de ambas colecciones de microorganismos. Si bien es cierto que el árbol de la colección de A. zugana es más homogéneo que el de $R$. lebeau, en ambos casos se distinguen tres grupos de aislamientos con un comportamiento enzimático similar. Estos árboles no establecen ningún tipo de relación filogenética, más bien agrupan a los microorganismos estudiados de acuerdo con su capacidad de utilizar los sustratos analizados, y sugiere una posible relación ecológica más que evolutiva. 


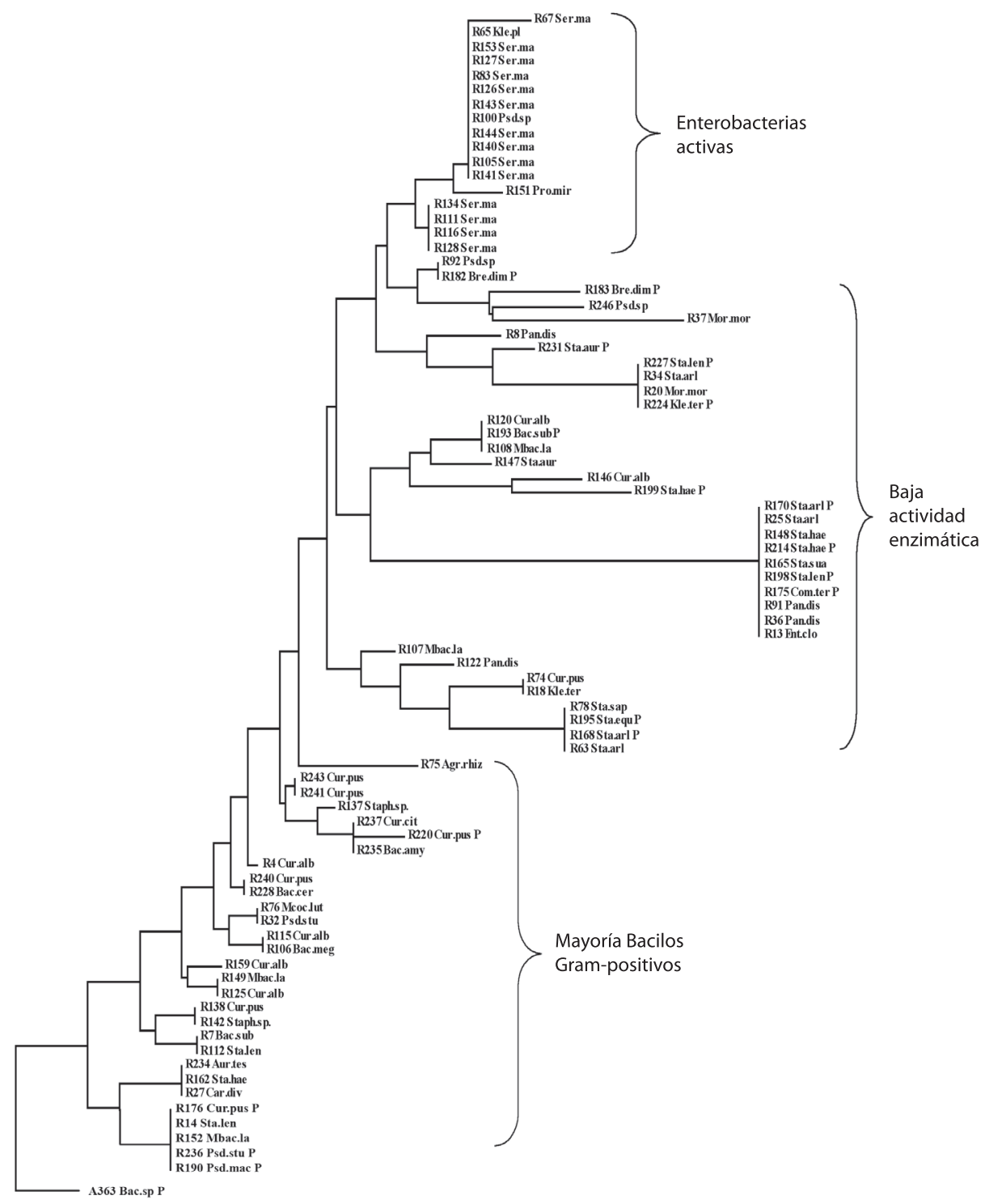

Fig. 2. Agrupamiento de los aislamientos bacterianos provenientes de $R$. lebeau de acuerdo con sus actividades enzimáticas. El árbol fue construido empleando el programa informático Treecon para Windows, versión 1.3b (Van de Peer y de Wachter 1994), usando el método de Neighbor-Joining. Para cada aislamiento, se asignó un valor de 1 ó 0 para cada ensayo enzimático, según este fuese positivo o negativo. La matriz obtenida se proceso según las indicaciones del programa informático. Más detalles sobre la construcción del árbol se hallan en la sección de materiales y métodos. Aislamientos obtenidos del contenido de pupas poseen una letra "P" al final de su código de identificación. Este es un árbol fenotípico basado en actividades enzimáticas y no refleja necesariamente relaciones filogenéticas entre los aislamientos evaluados. Ver texto para interpretación de los resultados.

Fig. 2. Grouping of bacterial isolates obtained from $R$. lebeau according to their enzymatic activities. The tree was constructed employing the software Treecon for Windows, version 1.3b (Van de Peer and de Wachter 1994), using the NeighborJoining algorithm. For each isolate, a value of 1 or 0 was assigned for each enzymatic test, depending on whether the test was positive or negative. The obtained matrix was processed according to the instructions of the Treecon software. For more details on the construction of the tree, see materials and methods. Isolates obtained from pupae samples are labeled with a letter "P" after their identification code. This is a phenotypic tree based on enzymatic activities and does not reflect necessarily phylogenetic relationships between the isolates evaluated. See text for interpretation of the obtained results. 


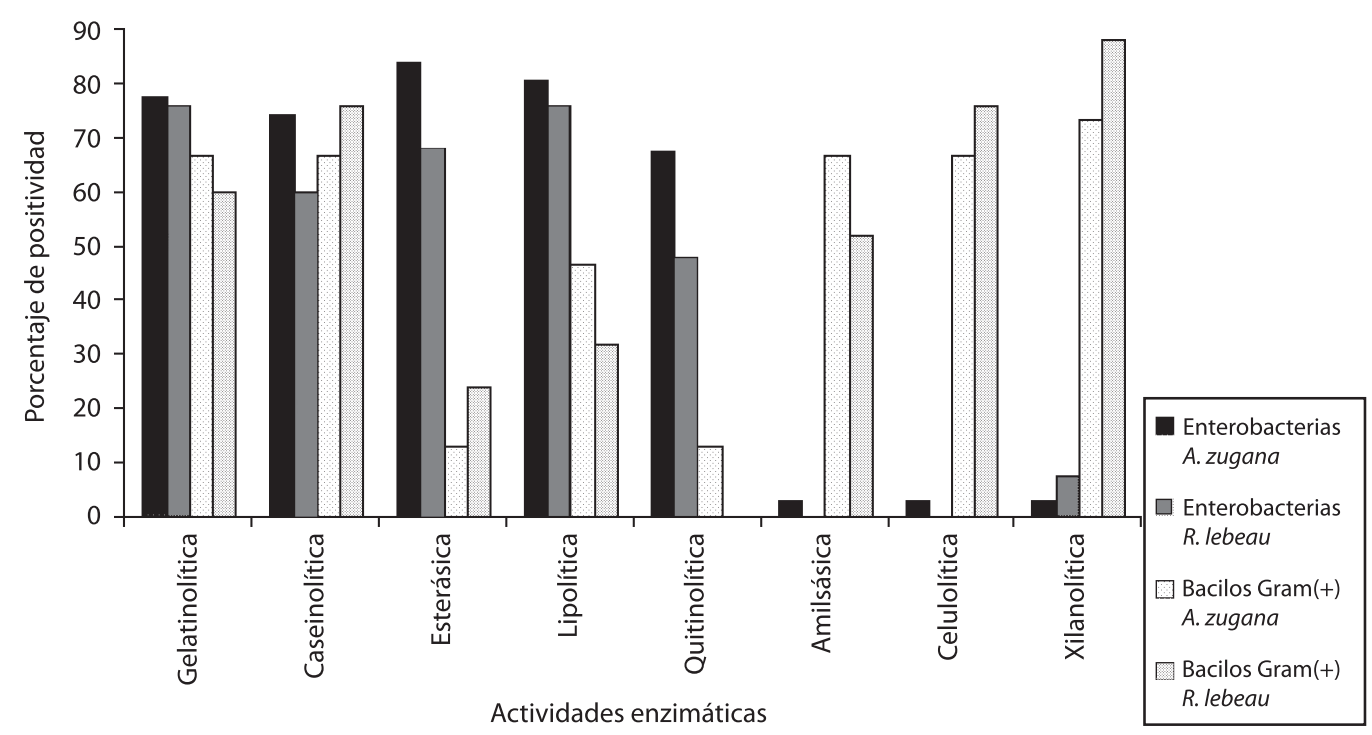

Fig. 3. Porcentaje de positividad en actividades enzimáticas evaluadas para diferentes grupos de aislamientos bacterianos. De todos los aislamientos bacterianos evaluados en este estudio, se seleccionaron cuatro grupos para comparar su comportamiento enzimático: aislamientos de la familia Enterobacteriaceae provenientes de A. zugana, aislamientos de Enterobacteriaceae provenientes de $R$. lebeau, bacilos Gram-positivos aislados de A. zugana y bacilos Gram-positivos aislados de $R$. lebeau. El porcentaje de positividad corresponde a la relación entre el número de aislamientos positivos para una determinada actividad y el número de aislamientos evaluados en cada categoría. Detalles sobre la realización de los ensayos enzimáticos se hallan en la sección de materiales y métodos. Ver texto para interpretación de los resultados.

Fig. 3. Percent of positive enzymatic activity tests for selected groups of bacterial isolates. From all evaluated bacterial isolates in this study, four groups were selected to compare their enzymatic profile: isolates of the Enterobacteriaceae family obtained from A. zugana, Enterobacteriaceae isolates obtained from $R$. lebeau, Gram-positive bacilli obtained from $A$. zugana and Gram-positive bacilli obtained from $R$. lebeau. The percent of positive tests corresponds to the relation between the number of isolates with positive activity for a certain enzymatic activity and the total number of isolates evaluated for such activity in each group. For details on the execution of the enzymatic tests, see materials and methods. See text for interpretation of the obtained results.

La implicación de estos hallazgos en la ecología del intestino como microhábitat requiere estudios más profundos y complejos. La alta competencia en el intestino de las orugas podría fomentar la aparente especialización en sustratos. Las enterobacterias constituyen los aislamientos más frecuentes en ambas poblaciones, hallazgo que concuerda con estudios similares en tractos digestivos de otros insectos (Eutick et al. 1978, Ulrich et al. 1981, Demaio et al. 1996). Podría ser ventajoso para el resto de microorganismos aprovechar aquellos sustratos que las enterobacterias no pueden utilizar (almidón, celulosa, xilano), en lugar de competir con ellas por los mismos sustratos. No obstante, la aparente especialización observada podría explicarse en el sentido inverso, es decir, que las enterobacterias se han concentrado en aquellos sustratos inaccesibles para el resto de las bacterias que colonizan este hábitat.

Adicionalmente, el comportamiento enzimático descrito podría ser resultado de adaptaciones para sobrevivir en un nicho particular. Se ha demostrado que xilanasas y celulasas son importantes para colonizar la superficie de hojas, por lo que se les ha relacionado con patogenicidad en plantas (Lucas 1998). Quizá los bacilos Gram-positivos están más adaptados a vivir en la superficie de hojas que en el intestino de las orugas, aunque la presencia de tejido vegetal dentro del intestino podría representar para ellos una fuente de energía. Por otro lado, sustratos como lípidos y quitina son mucho más abundantes dentro del intestino 
de orugas que en la superficie de las hojas. La degradación de estos sustratos, casi exclusiva de enterobacterias, podría reflejar una adaptación de este grupo al intestino. Muchas de las especies bacterianas analizadas en este trabajo, tanto enterobacterias como bacilos Grampositivos, han sido halladas como endófitos en diferentes plantas (Kobayashi y Palumbo 2000) Las condiciones particulares del intestino podrían seleccionar aquellos microorganismos con mayor capacidad enzimática. Para confirmar estas hipótesis es necesario analizar el comportamiento enzimático de un mayor número de aislamientos provenientes de hojas de plantas hospederas. A la vez, es importante señalar que las características de este estudio no permiten afirmar que las enzimas estudiadas estén siendo expresadas por las bacterias dentro del intestino del insecto. La respuesta a esta incógnita permanece abierta a futuras investigaciones.

Para cada sustrato evaluado se obtuvo una subcolección de aislamientos bacterianos con actividad enzimática, a partir de un ambiente extremo como el tracto digestivo de orugas. Esto podría representar un punto de partida para estudios posteriores en los que se desee profundizar en una actividad en particular. Todas las actividades evaluadas han sido utilizadas en distintos procesos de importancia económica y son de uso común en la industria. Sin embargo, las quitinasas son las enzimas dentro de este grupo que poseen mayor número de aplicaciones biotecnológicas, sobre todo en el control biológico de plagas agrícolas (Cohen-Kupiec y Chet 1998, Patil et al. 2000). Diferentes quitinasas han sido aisladas, purificadas y clonadas a partir de diversas bacterias, principalmente especies de los géneros Bacillus, Enterobacter, Serratia, Pseudomonas, Vibrio, Aeromonas y Streptomyces (Thompson et al. 2001). En este estudio, se obtuvieron 23 aislamientos quitinolíticos a partir de muestras de A. zugana. De ellos, 21 aislamientos correspondían a enterobacterias y solamente dos a bacilos Gram-positivos (ninguno de ellos $B$. thuringiensis). En el caso de $R$. lebeau, de 13 aislamientos quitinolíticos, 12 pertenecen a la familia Enterobacteriaceae y solamente uno corresponde al género Pseudomonas. Por tanto, en los aislamientos de tractos digestivos de orugas analizados, la actividad quitinolítica es prácticamente exclusiva de enterobacterias, principalmente de la especie Serratia marcescens.

$B$. thuringiensis es considerado un exitoso agente microbiano de control biológico y es empleado en una gran variedad de bioinsecticidas en el mundo entero (Barboza-Corona et al. 1999). Su presencia en tractos digestivos de orugas en ecosistemas protegidos resulta interesante, pues las orugas que constituyen plagas agrícolas son blancos usuales de las proteínas insecticidas de $B$. thuringiensis (Hofte y Whiteley 1989). Se ha demostrado que las quitinasas tienen un efecto sinérgico con las proteínas insecticidas de B. thuringiensis, incrementando la capacidad de la bacteria para inducir patología en insectos (Sampson y Gooday 1998). Este sinergismo se debe a que las quitinasas degradan la membrana peritrófica del intestino del artrópodo, facilitando el acceso de las toxinas a sus células blanco, las células epiteliales del tracto digestivo (Regev et al. 1996). Aunque se han identificado cepas de $B$. thuringiensis productoras de quitinasas (Barboza-Corona et al. 1999, Rojas-Avelizapa et al. 1999), nosotros no hallamos aislamientos de esta bacteria con actividad quitinolítica. Dicha actividad tampoco fue detectada en 25 aislamientos de $B$. thuringiensis provenientes de plantas hospederas, intestinos y heces de orugas tropicales (Rodríguez 2001). Por lo tanto, la degradación de quitina en el microambiente bajo estudio parece ser exclusiva de enterobacterias, al menos en el apartado de bacterias cultivables aerobias.

Finalmente, es importante indicar que este estudio consideró solamente bacterias cultivables en medios ricos y aerobios, las cuales representan una pequeña fracción de la microbiota presente en los materiales analizados (Hugenholtz et al. 1998). De igual modo, los ensayos enzimáticos fueron realizados a $\mathrm{pH}$ neutro, por lo que no se valoraron enzimas cuya actividad es observable únicamente en medio alcalino. Por lo tanto, el potencial biotecnológico de las bacterias en el microhábitat 
del intestino de orugas y el contenido de pupas podría ser mayor. El uso de métodos tradicionales de aislamiento de bacterias y detección de actividad enzimática representa una alternativa complementaria a las técnicas de Biología Molecular independientes de cultivo. Los resultados de este trabajo podrán servir de referencia para investigaciones orientadas al aprovechamiento biotecnológico de los microorganismos que habitan en intestinos de orugas, tanto en la industria como en la agricultura.

\section{AGRADECIMIENTOS}

Los autores expresan su especial agradecimiento al Área de Conservación Guanacaste y su personal por apoyo logístico y administrativo a este proyecto. A Salvador Amato, por facilitar sus metodologías para analizar secreto-enzimas bacterianas en aislamientos del suelo. Este trabajo fue financiado por el programa UNESCO/ MIRCEN (Contrato 885.035-1), por el Consejo Nacional de Investigaciones Científicas y Tecnológicas de Costa Rica (CONICIT, Refs $3-208-99$ y $163-00 F I)$ y por la Vicerrectoría de Investigación de la Universidad de Costa Rica (VI 801-99-506), y facilitado por los proyectos NSF DEB 9400829, DEB 9705072 a D.H. Janzen y NSF 0084224.

\section{RESUMEN}

El tracto digestivo de orugas constituye un microambiente extremo, debido a su elevado $\mathrm{pH}$ y presencia de sustancias antimicrobianas secretadas por el insecto o derivadas del tejido vegetal ingerido. Al mismo tiempo, el intestino alberga gran cantidad de alimento, por el cual los microorganismos presentes podrían competir entre sí y con su hospedero. Existe poca información sobre la microbiota asociada con el intestino de orugas tropicales, aunque se ha demostrado la presencia de bacterias de diversos géneros tanto en el intestino como en el interior de pupas. El estudio de las actividades enzimáticas de estos microorganismos constituye un punto de partida en la comprensión de la posible relación metabólica y fisiológica que establecen con sus hospederos, a la vez que permite investigar enzimas con potenciales aplicaciones biotecnológicas. En este trabajo se evaluó la presencia de actividades gelatinolítica, caseinolítica, esterásica, lipolítica, quitinolítica, amilásica, celulolítica y xilanolítica en dos colecciones de aislamientos bacterianos provenientes de tractos digestivos de orugas y de pupas de los lepidópteros Automeris zugana y Rothschildia lebeau. Se utilizaron ensayos bioquímicos tradicionales para detectar enzimas secretadas en condiciones aerobias, en las que ambas colecciones exhibieron un comportamiento enzimático similar. Ningún aislamiento produjo un resultado positivo en todas las pruebas, pero como conjunto ambas colecciones fueron capaces de utilizar todos los sustratos evaluados. Los aislamientos obtenidos de pupas presentaron prácticamente las mismas actividades que sus homólogos provenientes de intestinos. En ambas colecciones fue posible agrupar los aislamientos de acuerdo con su patrón de producción de enzimas. Además de un conjunto heterogéneo de aislamientos poco activos (dos o menos actividades), se destacan dos grupos muy activos (al menos cinco actividades), que manifiestan una aparente especialización en los sustratos que utilizan. El primero de ellos está constituido exclusivamente por miembros de la familia Enterobacteriaceae, los cuales exhibieron un alto porcentaje de positividad en actividades lipolítica y quitinolítica, pero no demostraron la expresión de las actividades amilásica, celulolítica ni xilanolítica. El segundo grupo, formado en su gran mayoría por bacilos Gram-positivos, presenta la situación opuesta: alta positividad en actividades amilásica, celulolítica y xilanolítica, no detección de actividad quitinolítica y pocos aislamientos con actividad lipolítica. Este trabajo pretende ser la base de futuras investigaciones que exploren el potencial biotecnológico de aislamientos bacterianos provenientes del tracto digestivo de orugas.

Palabras clave: Saturniidae, oruga, enzimas bacterianas, Automeris zugana, Rothschildia lebeau, Área de Conservación Guanacaste, Costa Rica.

\section{REFERENCIAS}

Barboza-Corona, J.E., J.C. Contreras, R. VelásquezRobledo, M. Bautista-Justo, M. Gómez-Ramírez, R. Cruz-Camarillo \& J.E. Ibarra. 1999. Selection of chitinolytic strains of Bacillus thuringiensis. Biotechnol. Lett. 21: 1125-1129.

Broderick, N.A., K.F. Raffa, R.M. Goodman \& J. Handelsman. 2004. Census of the bacterial community of the gypsy moth larval midgut using culturing and culture-independent methods. Appl. Environ. Microbiol. 70: 293-300.

Brune, A. 1998. Termite guts: the world's smallest bioreactors. Trends Biotechnol. 16: 16-21.

Castañeda-Argulló, M. 1956. Studies on the biosynthesis of extracellular proteases by bacteria. J. Gen. Physiol. 89: 369-373. 
Cohen-Kupiec, R. \& I. Chet. 1998. The molecular biology of chitin digestion. Curr. Opin. Biotechnol. 9: 270277.

Chernin, L., Z. Ismailov, S. Haran \& I. Chet. 1995. Chitinolytic Enterobacter agglomerans antagonistic to fungal plant pathogens. Appl. Environ. Microbiol. 61: $1720-1726$.

Chernin, L., L. Fuente, V. Sobolev, S. Haran, C.E. Vorgias, A.B. Oppenheim \& I. Chet. 1997. Molecular cloning, structural analysis and expression in Escherichia coli of a chitinase gene from Enterobacter agglomerans. Appl. Environ. Microbiol. 63: 834-839.

Christov, L.P., G. Szakacs \& H. Balakrishnan. 1999 Production, partial characterization and use of fungal cellulase-free xylanases in pulp-bleaching. Process Biochem. 34: 511-517.

De Vries, R.P. \& J. Visser. 2001. Aspergillus enzymes involved in degradation of plant cell wall polysaccharides. Microbiol. Mol. Biol. Rev. 65: 497-522.

Demaio, J., C.B. Pumpuni, M. Kent \& J.C. Beier. 1996. The midgut bacterial flora of wild Aedes triseriatus, Culex pipiens and Psorophora columbiae mosquitoes. Am. J. Trop. Med. Hyg. 54: 219-223.

Dow, J.A. 1992. pH gradients in Lepidopteran midgut. J. Exp. Biol. 172: 355-375.

Downing, K.J. \& J.A. Thompson. 2000. Introduction of the Serratia marcescens chiA gene into an endophytic Pseudomonas aeruginosa for the biocontrol of phytopathogenic fungi. Can. J. Microbiol. 46: 363-369.

Downing, K.J., G. Leslie \& J.A. Thomson. 2000. Biocontrol of the sugarcane borer Eldana sacharina by expression of the Bacillus thuringiensis cry1Ac7 and Serratia marcescens chiA genes in sugarcaneassociated bacteria. Appl. Environ. Microbiol. 66: 2804-2810.

Eutick, M.L., R.W. O’Brien \& M. Salytor. 1978. Bacteria from the gut of Australian termites. Appl. Environ. Microbiol. 35: 823-828.

Fontecha, G. 2002. Análisis de la diversidad procariota en el intestino de $R$. lebeau (Lepidoptera: Saturniidae) mediante los polimorfismos en los fragmentos terminales de restricción del gen ARNr 16S. Tesis de Maestría, Universidad de Costa Rica, San José, Costa Rica. $175 p$

Hershkovitz, M.A. \& D.D. Leipe. 1998. Phylogenetic analysis, p 189-230. In A.D. Baxevanis \& B.F.F Ouellette (eds.). Bioinformatics: A practical guide to the analysis of genes and proteins. Wiley, Nueva York, EEUU.

Hirano, S. 1996. Chitin biotechnology applications. Biotechnol. Annu. Rev. 2: 237-258.

Hofte, H. \& H.R. Whiteley. 1989. Insecticidal crystal proteins of Bacillus thuringiensis. Microbiol. Rev. 53: $242-255$.

Horikoshi, K. 1999. Alkaliphiles: some applications of their products for biotechnology. Microbiol. Mol. Biol. Rev. 63: 735-750.

Hugenholtz, P., B.M. Goebel \& N.R. Pace. 1998. Impact of culture-independent studies on the emerging phylogenetic view of bacterial diversity. J. Bacteriol. 180: 4765-4774.

Janzen, D.H. 1981. Patterns of herbivory in a tropical deciduous forest. Biotropica 13: 271-282.

Janzen, D.H. 1984. Two ways to be a tropical big moth: Santa Rosa saturniids and sphingids. Oxford Surv. Evol. Biol. 1: 85-140.

Janzen, D.H. 1985. A host plant is more than its chemistry. Illinois Natur. Hist. Bull. 33: 141-174.

Janzen, D.H. 1993. Caterpillar seasonality in a Costa Rican dry forest, p 448-477. In N.E. Stamp \& T.E. Casey (eds.). Caterpillars. Ecological and evolutionary constraints on foraging. Chapman \& Hall, Nueva York, EEUU.

Janzen, D.H. \& I.D. Gauld. 1997. Patterns of use of large moth caterpillars (Lepidoptera: Saturniidae and Sphingidae) by ichneumonid parasitoids (Hymenoptera) in Costa Rican dry forest, p. 251271. In A.D. Watt, N.E. Stork \& M.D. Hunter (eds.). Forests and insects. Chapman \& Hall, Londres, Inglaterra.

Kobayashi, D.Y. \& J.D. Palumbo. 2000. Bacterial endophytes and their effects on plants and uses in agriculture, p. 199-233. In C.W. Bacon \& J.F. White Jr. (eds). Microbial endophytes. Marcel Dekker, Nueva York, EEUU.

Lengeler, J.W., G. Drews \& H.G. Schlegel. 1999. Biology of the Prokaryotes. Thieme Stuttgart, Nueva York, EEUU.

Lucas, J.A. 1998. Plant pathology and Plant Pathogens. Blackwell, Oxford, Inglaterra. p. 123-139.

McLellan, M.R., A.J. Cowling, M. Turner \& J.G. Day. 1991. Maintenance of algae and protozoa, p. 184-226. 
In B.E. Kirshop \& A. Doyle (eds.). Maintenance of Microorganisms. Academic, Londres, Inglaterra.

Patil, R.S., V. Ghormade \& M.V. Deshpande. 2000. Chitinolytic enzymes: an exploration. Enzyme Microb. Technol. 26: 473-483.

Regev, A., M. Keller, N. Strizhov, B. Sneh, E. Prudovsky, I. Chet, I. Ginzberg, Z. Koncz-Kalman, C. Koncz, J. Schell \& A. Zilberstein. 1996. Synergistic activity of a Bacillus thuringiensis $\delta$-endotoxin and a bacterial endochitinase against Spodoptera littoralis larvae. Appl. Environ. Microbiol. 62: 3581-3586.

Rodríguez, C. 2001. Aislamiento y caracterización parcial de Bacillus thuringiensis a partir de las plantas hospederas, tractos intestinales y excrementos de larvas de mariposas recolectadas en ecosistemas protegidos. Trabajo Final de Graduación, Universidad de Costa Rica, San José, Costa Rica. 51 p.

Rojas-Avelizapa, L.I., R. Cruz-Camarillo, M.I. Guerrero, R. Rodríguez-Vázquez \& J.E. Ibarra. 1999. Selection and characterization of a proteochitinolytic strain of Bacillus thuringiensis, able to grow in shrimp waste media. Biotechnol. Lett. 22: $261-268$

Rondon, M.R., S.J. Raffel, R.M. Goodman \& J. Handelsman. 1999. Toward functional genomics in bacteria: analysis of gene expression in Escherichia coli from a bacterial artificial chromosome library of Bacillus cereus. Proc. Natl. Acad. Sci. USA 96: 6451-6455.

Rondon, M.R., P.R. August, A.D. Bettermann, S.F. Brady, T.H. Grossman, M.R. Liles, K.A. Loiacono, B.A. Lynch, I.A. MacNeil, C. Minor, C.L. Tiong, M. Gilman, M.S. Osburne, J. Clardy, J. Handelsman \& R.M. Goodman. 2000. Cloning the soil metanogenome: a strategy for accessing the genetic and functional diversity of uncultured microorganisms. Appl. Environ. Microbiol. 66: 2541-2547.

Russell, V.W. \& P.E. Dunn. 1991. Lysosyme in the midgut of Manduca sexta during metamorphosis. Arch. Insect. Biochem. Physiol. 17: 67-80.

Sampson, M.N. \& G.W. Gooday. 1998. Involvement of chitinases of Bacillus thuringiensis during pathogenesis in insects. Microbiology 144: 2189-2194.

Schultz, J.C. 2002. How plants fight dirty. Nature 416: 267.

Sittenfeld, A., L. Uribe-Lorío, M. Mora, V. Nielsen, G. Arrieta \& D.H. Janzen. 2002. Does a polyphagous caterpillar have the same gut microbiota when feeding on different species of food plants? Rev. Biol. Trop. 50: 547-560.

Thompson, S.E., M. Smith, M.C. Wilkinson \& K. Peek. 2001. Identification and characterization of a chitinase antigen from Pseudomonas aeruginosa strain 385. Appl. Environ. Microbiol. 67: 4001-4008.

Ulrich, R.G., D.A. Buthala \& M.J. Klug. 1981. Microbiota associated with the gastrointestinal tract of the common house cricket, Acheta domestica. Appl. Environ. Microbiol. 41: 246-254.

Van de Peer, Y. \& R. de Wachter. 1994. TREECON for Windows: a software package for the construction and drawing of evolutionary trees for the Microsoft Windows environment. Comput. Appl. Biosci. 10: 569-570.

Whitman, W.B., D.C. Coleman \& W.J. Wiebe. 1998. Prokaryotes: the unseen majority. Proc. Natl. Acad. Sci. USA. 95: 6578-6583. 
